\title{
Сравнение состава нефелиновых сиенитов краевой и центральной частей Хибинского массива
}

Коноплёва Н.Г. ${ }^{1}$, Пахомовский Я.А. ${ }^{1,2}$, Яковенчук В.Н. ${ }^{1,2}$, Михайлова Ю.А. ${ }^{1,2}$, Иванюк Г.Ю.

${ }^{1}$ Центр наноматериаловедения КНЦ РАН, Anamumbl,n.konopleva@ksc.ru

${ }^{2}$ Геологический институт КНЦ РАН, Anamumbl, geoksc@geoksc.apatity.ru

Аннотация. Нефелиновые сиениты краевой (хибиниты) и центральной (фойяиты) частей массива имеют идентичный состав. Тренды изменения состава нефелиновых сиенитов от края массива к его центру, а также симметричное относительно кольцевой зоны фоидолитов распределение практически всех компонентов их минерального и химического состава свидетельствуют в пользу дифференциации единого тела фойяитов под воздействием формирующегося комплекса пород Главного кольца.

Ключевые слова: Хибинский массив,нефелиновые сиениты, фойяиты, хибиниты, фоидолиты.

\section{Comparison of nepheline syenites composition in the outside and central parts of the Khibiny massif}

\author{
Konopleva N.G. ${ }^{1}$, Pakhomovsky Ya.A. ${ }^{1,2}$, Yakovenchuk V.N. ${ }^{1,2}$, Mikhailova Yu.A. ${ }^{1,2}$,Ivanyuk G.Yu. \\ ${ }^{1}$ Nanomaterials Research Centre KSC RAS, Apatity,n.konopleva@ksc.ru \\ ${ }^{2}$ Geological Institute KSC RAS, Apatity, geoksc@geoksc.apatity.ru
}

\begin{abstract}
Nepheline syenites of the outside (khibinite) and central (foyaite) parts of the massif have identical composition. Trends of changes in the composition of nepheline syenites from the edge of the massif to its center and a symmetric distribution of practically all components of their mineral and chemical composition relative to the annular zone of foidolite indicate the differentiation of a single body foyaites under the influence of the emerging rock complex of the Main ring.
\end{abstract}

Key words: Khibiny massif, nepheline syenite, foyaite, khibinite, foidolite.

Наиболее распространёнными породами Хибинского массива (рис. 1) являются нефелиновые сиениты - фойяиты, слагающие около 70 \% площади массива. Тело фойяитов разделено на две приблизительно равные части Главной кольцевой зоной фоидолитов (мельтейгит-уртитов), окаймлённых оторочкой обогащённых калием нефелиновых сиенитов (рисчорритов) и/или неравнозернистых нефелиновых сиенитов («лявочорритов»). Во внешней относительно Главного кольца части массива расположена еще одна полукольцевая зона (Малая дуга) мельтейгит-уртитов, малиньитов и мелкозернистых щелочных и нефелиновых сиенитов (фенитов) с ксенолитами вулканогенноосадочных пород.

Для объяснения концентрически-зональной структуры массива предложено множество генетических схем, основные из которых можно условно разделить на три группы, базирующиеся на сходных положениях: 1) формирование единой интрузии хибинитов-фойяитов с последующим внедрением расплавов по кольцевому разлому (Ферсман, 1931, 1941; Куплетский, 1932, 1937; Гуткова, 1934; Сняткова и др., 1983; Иванюк и др., 2009); 2) многофазная интрузия с формированием от периферии к центру всё более молодых породных комплексов (Елисеев, 1939; Зак и др., 1972; Галахов, 1975; Арзамасцев, 1998); 3) многофазная интрузия с формированием от центра к периферии всё более молодых породных комплексов (Антонов, 1934; Влодавец, 1935).

В данной статье мы сравним состав нефелиновых сиенитов краевой и центральной частей массива - хибинитов и фойяитов, чтобы понять, насколько обоснованно ряд исследователей относят их к разным интрузивным фазам. Материалом для сравнения послужили результаты изучения образцов пород, отобранных по профилю $A-B-C-D-E-F$ от западного края массива (точка $A$ ) через Малую дугу $(B)$ и западную часть Главного кольца $(C)$ к центру массива $(D)$ и далее через месторождение Коашва $(E)$ к южному краю массива $(F)$. 


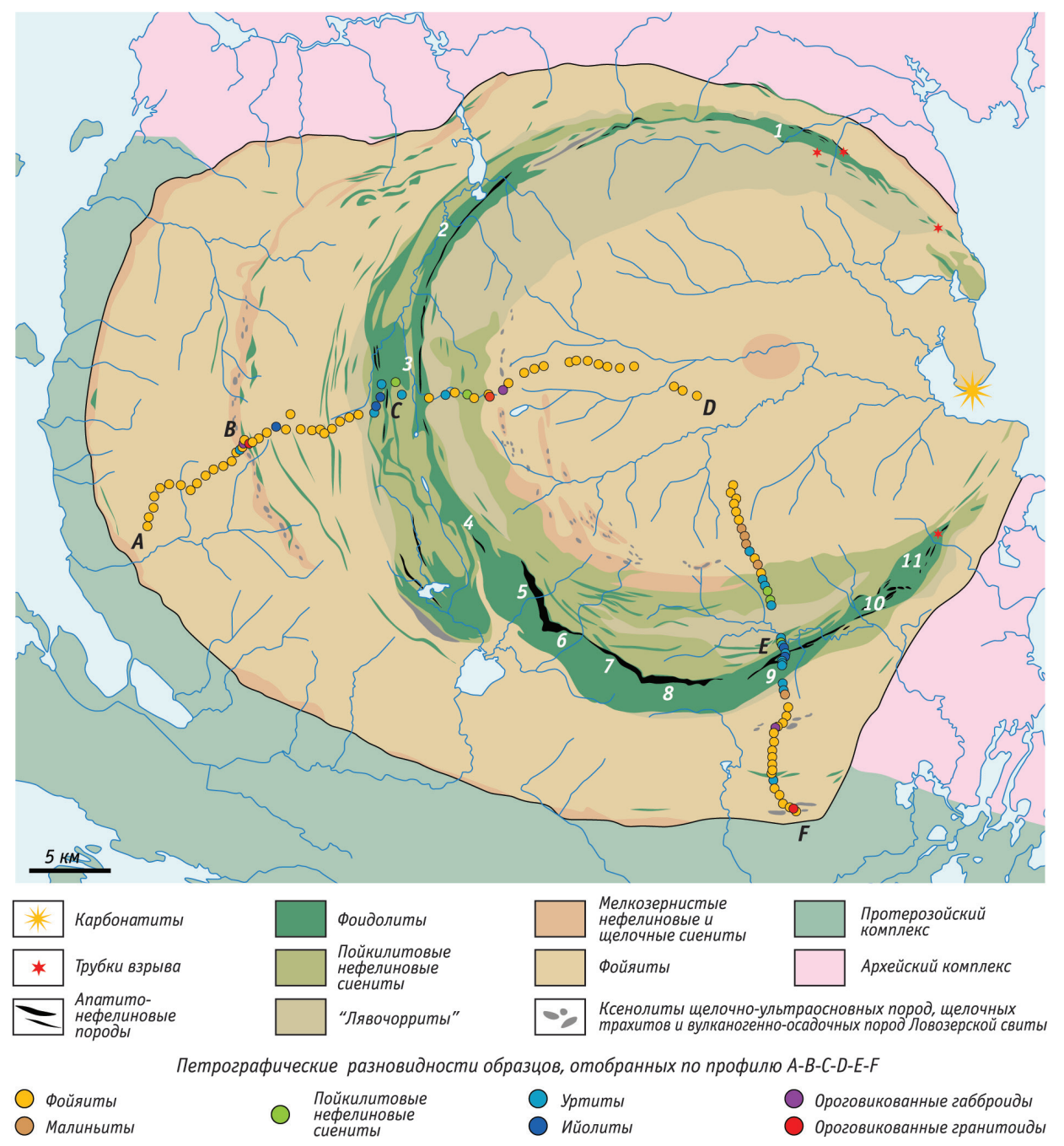

Рис. 1. Схема геологического строения Хибинского массива (Сняткова и др., 1983, с упрощениями).

Fig. 1. Simplified geology map of the Khibiny massif (after Snyatkova et al., 1983.).

В соответствии с классификацией $Q A P F$ Международного союза геологических наук (Классификация..., 1997) условная граница нефелиновых сиенитов с фоидолитами проходит по линии $\mathrm{Fsp}_{60} \mathrm{Nph}_{40}$, а со щелочными сиенитами - по линии $\mathrm{Fsp}_{90} \mathrm{Nph}_{10}$ (рис. 2). По цветовому индексу M нефелиновые сиениты подразделяются на фойяиты ${ }^{1}$ ( $<30 \%$ темноцветных минералов), малиньиты (30-60\%) и шонкиниты (> $30 \%)$.

На классификационной диаграмме видно, что количественное соотношение полевого шпата, нефелина и темноцветных минералов в составе нефелиновых сиенитов (хибинитов-фойяитов) по профилю $A-F$ варьирует в широких пределах, однако поля их составов полностью перекрываются (рис. 2), и по минеральному составу хибиниты (в среднем $\mathrm{Fsp}_{45} \mathrm{Nph}_{40} \mathrm{M}_{15}$ ) ничем не отличаются от фойяитов(в среднем $\mathrm{Fsp}_{44} \mathrm{Nph}_{40} \mathrm{M}_{16}$ ), равно как и по содержанию основных петрохимических компонентов (рис. 3) и среднему химическому и минеральному составу (рис. 4).Приведённые в работах предыдущих исследователей поля составов и данные о средних содержаниях компонентов нефелиновых сиенитов также мало различаются (Куплетский, 1937; Зак и др., 1972; Галахов, 1975). Поэтому ключевым моментом в нашем исследовании стало выявление характера зональности массива в целом и нефелиновых сиенитов в частности.

\footnotetext{
${ }^{1}$ Для обозначения лейкократовой разновидности нефелиновых сиенитов используется термин фойяит, поскольку в указанной классификации корневое название нефелиновых сиенитов и название их лейкократовой разновидности совпадают, что не совсем удобно. К тому же термин фойяит был впервые использован для описания лейкократовых нефелиновых сиенитов Хибинского массива (Ramsay, Hackman, 1894)
} 


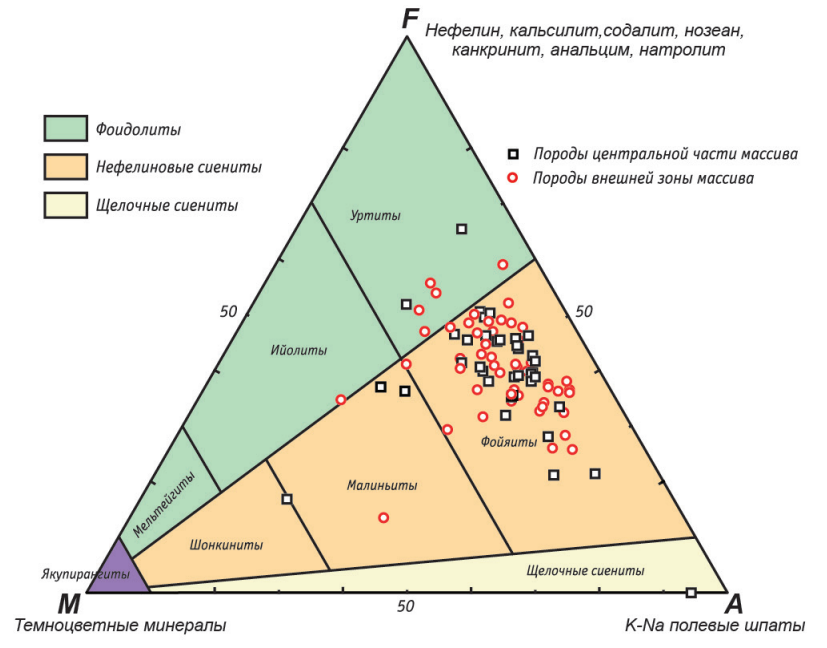

Рис. 2. Минеральный состав нефелиновых сиенитов по профилю A- F.

Fig. 2. Modal composition of nepheline syenites along the A-F profile.
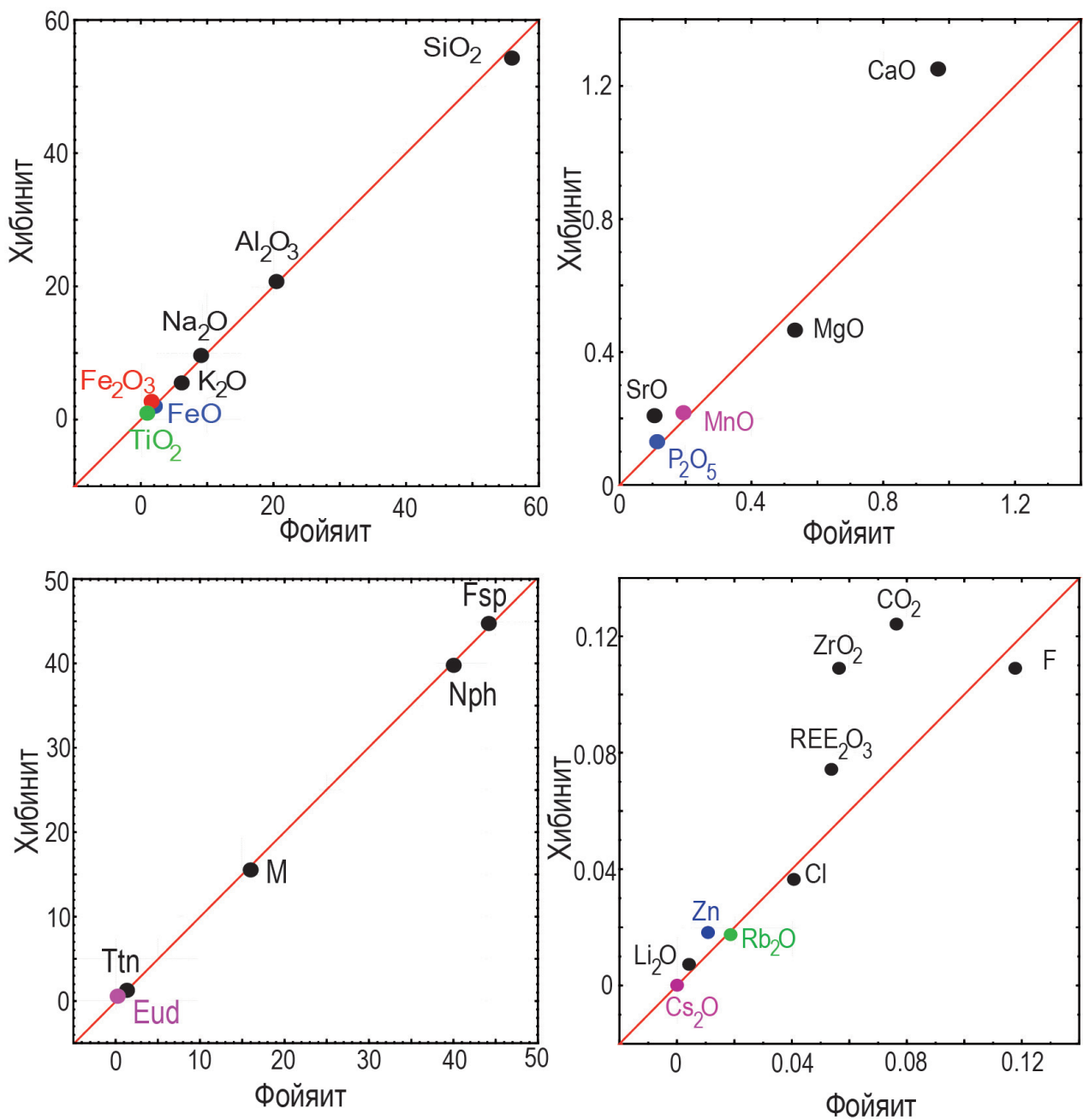

Рис. 4. Сопоставление среднего химического (мас. \%) и минерального (об. \%) состава хибинитов-фойяитов по профилю А-B-C-D-E-F.

Fig. 4. Comparison of the average chemical (wt. \%) and mineral (vol. \%) composition of khibinite and foyaite along the A-B-C-D-E-F profile. 


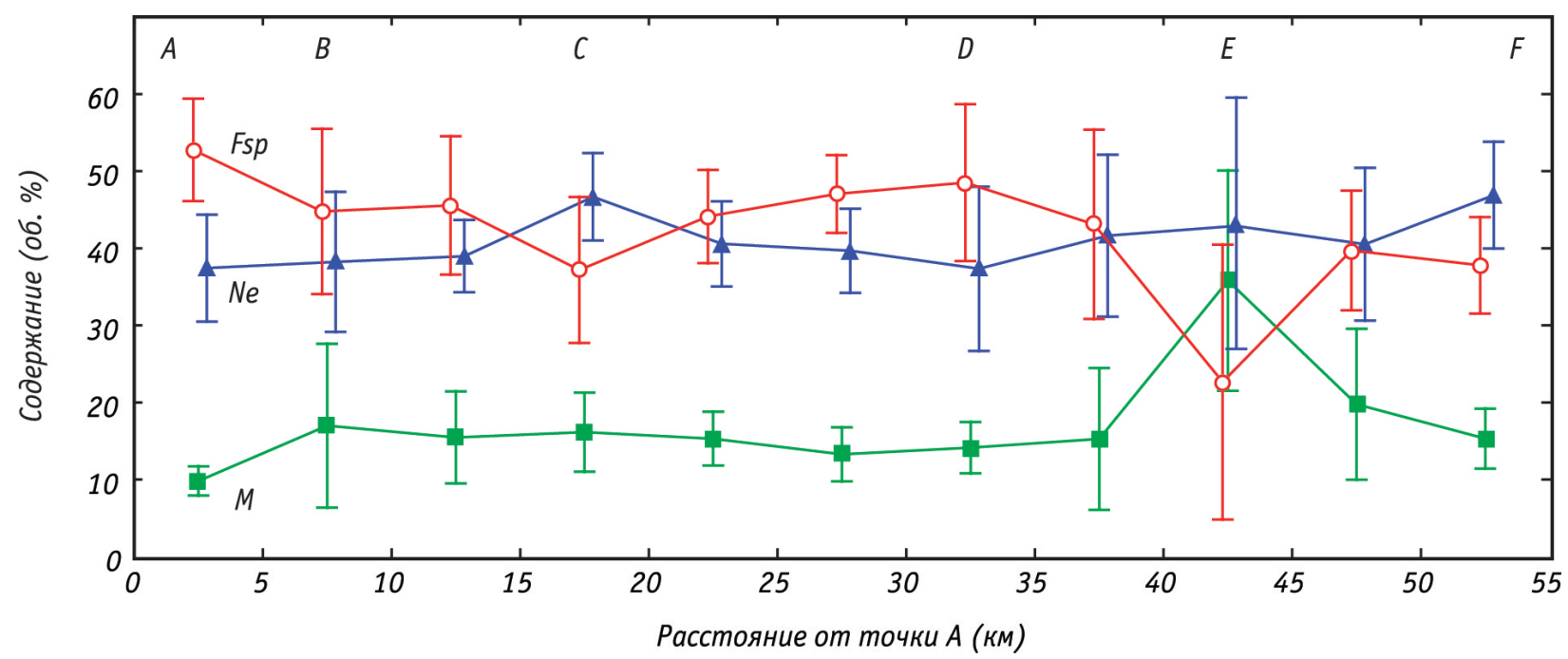

Рис. 5. Вариации содержания щелочных полевых шпатов (Fsp), нефелина (Ne) и темноцветных минералов (M) в нефелиновых сиенитах по профилю $A-F$.

Fig. 5. Variation of alkaline feldspar (Fsp), nepheline (Ne), and dark coloured minerals (M) contents along the $A-F$ profile.

Содержание главных породообразующих минералов в нефелиновых сиенитах изменяется по разрезу $A-F$ постепенно от периферии к центру массива с явно выраженной реакцией на зоны Малой дуги (точка $B$ ) и Главного кольца (точки $C$ и $E$ ).

Доля щелочных полевых шпатов в составе породы уменьшается к контакту с фоидолитами пропорционально мощности последних в разрезе (рис. 5): менее интенсивно в районе рудопроявлений Поачвумчорр и Пик Марченко (точка $C$,) и более интенсивно в районе месторождения Коашва (точка $E$ ). Это изменение компенсируется возрастанием содержания нефелина в точке $C$ и темноцветных минералов в точке $E$. В первом случае это приводит к образованию переходных к уртитамлейкократовых нефелиновых сиенитов или даже полевошпатовых уртитов, по своей структуре ещё соответствующих фойяитам, во втором - мезократовых нефелиновых сиенитов и малиньитов. Последовательное увеличение содержания полевого шпата к краевым частям массива (за счёт темноцветных минералов) и к его центру (за счёт нефелина) приводит к появлению здесь щелочных сиенитов - умптекитов (точка $A$ ) и пуласкитов (точка $D$ ).

Графики изменения химического состава нефелиновых сиенитов по указанному профилю (рис. 6) отражают ту же тенденцию. Часть элементов (K, $\left.\mathrm{Cl}, \mathrm{Fe}^{3+}, \mathrm{Mn}, \mathrm{Li}\right)$ имеют более или менее выраженные тренды изменения от краевой части массива к центру. На фоне этих трендов проявлены локальные максимумы или минимумы концентраций элементов в нефелиновых сиенитах, примыкающих к зоне Главного кольца и, в меньшей степени, Малой дуги. Изменение же концентраций большинства компонентов характеризуется кривыми, симметричными относительно Главного кольца, которое явно контролирует состав нефелиновых сиенитов (хибинитов-фойяитов). Изменения в их составе начинаются за 2-5 км от контакта с фоидолитами, причём, чем мощнее фоидолитовая толща, тем шире ореол изменения нефелиновых сиенитов.

По характеру концентраций все элементы в составе хибинитов-фойяитов можно условно разделить на две группы:

Элементы, одинаково реагирующие на зону Главного кольца в обоих участках её пересечения, к которой приурочены либо максимальные содержания элементов ( $\mathrm{Ti}, \mathrm{Fe}^{2+}, \mathrm{Mg}, \mathrm{Ca}, \mathrm{C}, \mathrm{Cl}, \mathrm{F}$ ), либо минимальные ( $\mathrm{Si}, \mathrm{H}, \mathrm{Li}$ ). Для $\mathrm{Fe}^{2+}$ и С наиболее интенсивные экстремумы приходятся на нефелиновые сиениты близ южного (рудного) сектора Главного кольца, а для Са - вблизи западной (слаборудной) его части и Малой дуги. Для $\mathrm{Cl}$ и $\mathrm{Li}$ эти изменения происходят на фоне монотонных трендов концентраций от периферии к центру массива. 
Центр массива
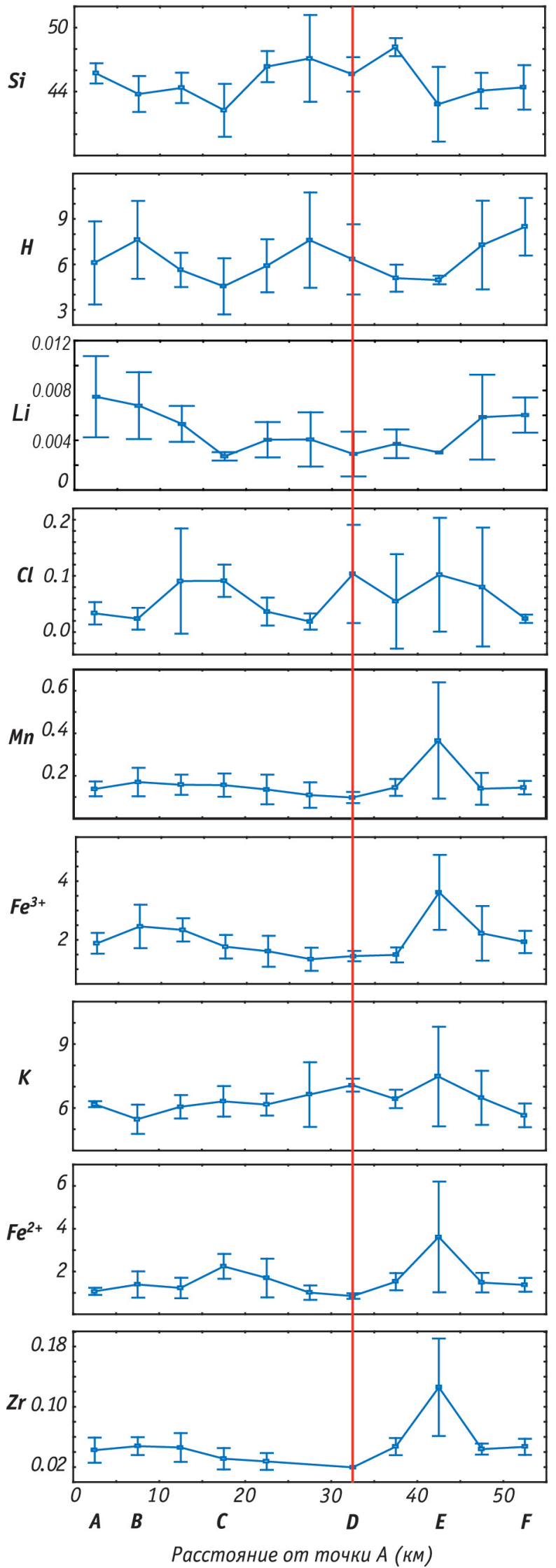

Центр массива
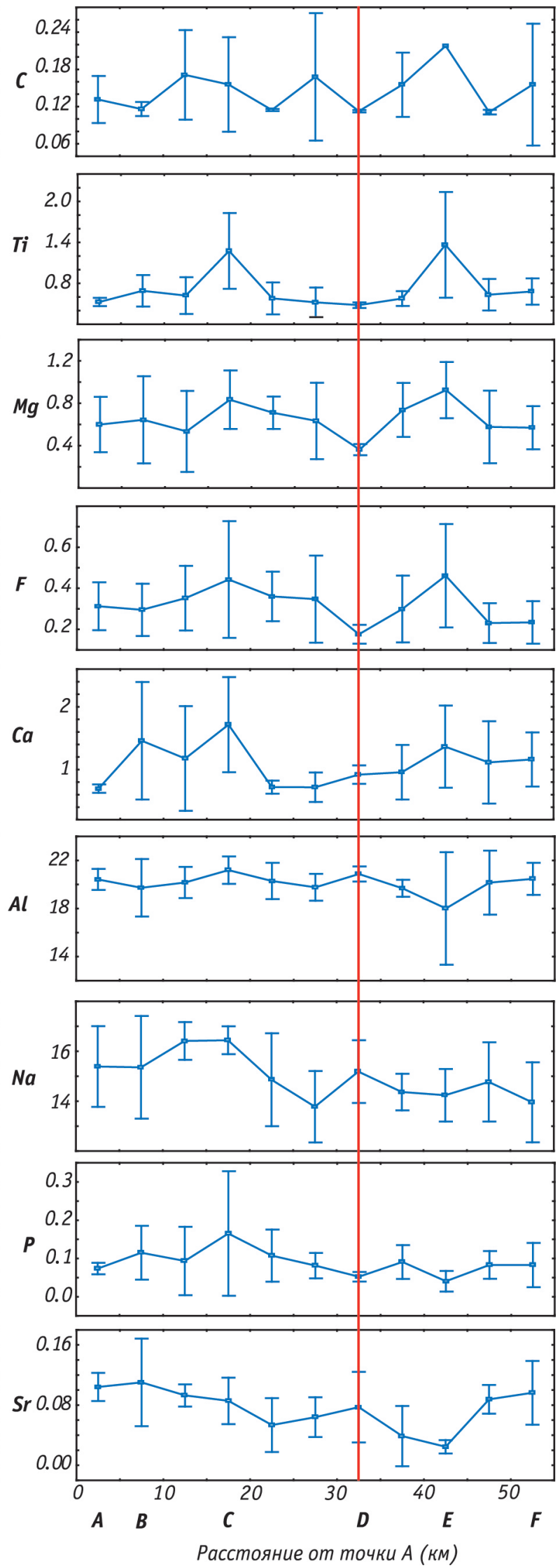

Рис. 6. Изменение состава нефелиновых сиенитов (ат. \% от бескислородной части) по профилю А - F. Fig. 6. Variation of the chemical composition of nepheline syenites along the A - F profile. 
Элементы, по-разному реагирующие на близость Главного кольца в его западном (слаборудном) и южном (рудном) секторах. Содержание $\mathrm{Al}, \mathrm{Na}, \mathrm{Pu} \mathrm{Sr}$ возрастает в нефелиновых сиенитах по мере приближения к безрудному сектору Главного кольца и Малой дуге ( $\mathrm{Sr})$, а в нефелиновых сиенитах близ рудного сектора Главного кольца, наоборот, уменьшается. Концентрации Cs, Rb и $\mathrm{REE}_{2} \mathrm{O}_{3}$ уменьшаются при приближении к безрудному сектору Главного кольца и Малой дуге $(\mathrm{Rb})$, но возрастают в нефелиновых сиенитах близ южного (рудного) сектора. Изменение концентраций $\mathrm{Mn}, \mathrm{Fe}^{3+}, \mathrm{K}$ иZr в западной части массива происходит постепенно, практически без какой-либо реакции на Малую дугу и Главное кольцо. В южной же части массива при сохранении указанных трендов происходит значительное обогащение нефелиновых сиенитов этими элементами в районе Коашвинского месторождения.

Таким образом, никаких различий в составе нефелиновых сиенитов (хибинитов-фойяитов) краевой и центральной частей массива, свидетельствующих в пользу их многоактного формирования, не обнаружено. Напротив, наличие более или менее явно выраженных трендов изменения состава нефелиновых сиенитов от края массива к его центру, а также симметричное относительно кольцевой зоны фоидолитов распределение практически всех компонентов в их минеральном и химическом составе противоречат гипотезе о многофазном происхождении комплекса нефелиновых сиенитов (массивные хибиниты, трахитоидные хибиниты, фойяиты) и свидетельствуют в пользу того, что все перечисленные породы - результат дифференциации единого тела фойяитов под воздействием формирующегося комплекса пород Главного кольца.

Исследования проводились в рамках научной темы ГИ КНЦ РАН 0226-2019-0051.

\section{Литература}

1. Антонов Л.Б. Апатитовые месторождения Хибинской тундры // Хибинские апатиты. Т. VII. Л. Изд-во: Госхимтехиздат. 1934. С. 1-197.

2. Арзамасцев А.А., Арзамасцева Л.В., Глазнев В.Н., Раевский А.Б. Глубинное строение и состав нижних горизонтов Хибинского и Ловозерского комплексов, Кольский полуостров: петролого-геофизическая модель // Петрология. 1998. Т. 6. № 5. С. 478-496.

3. Влодавец В.И. Пинуайвчорр-Юкспорр-Расвумчорр // Труды Арктического института. Т. 23. Л. Изд-во: Главсевморпути. 1935. С. 5-55.

4. Галахов А.В. Петрология Хибинского щелочного массива. Л. Изд-во: Наука. 1975. 256 с.

5. Гуткова Н.Н. К минералогии горы Юкспор (Хибинские тундры) // Материалы по петрографии и геохимии Кольского полуострова. Ч. 5. Труды СОПС. Серия Кольская. Вып. 8. Л. Изд-во: АН СССР. 1934. C. 7-105.

6. Елисеев Н.А., Ожинский И.С., Володин Е.Н. Геологическая карта Хибинских тундр // Труды Ленинградского геологического управления. Вып. 19. Л.-М. Изд-во: ГОНТИ. 1939. 68 с.

7. Зак С.И., Каменев Е.А., Минаков Ф.В., Арманд А.Л., Михеичев А.С., Петерсилье И.А. Хибинский щелочной массив. Л. Изд-во: Недра. 1972. 176 с.

8. Иванюк Г.Ю., Горяинов П.М., Пахомовский Я.А., Коноплёва Н.Г., Яковенчук В.Н., Базай А.В., Калашников А.О. Самоорганизация рудных комплексов. Синергетические принципы прогнозирования и поисков месторождений полезных ископаемых. М. Изд-во: ГЕОКАРТ - ГЕОС. 2009. 392 с.

9. Куплетский Б.М. Петрография Кольского полуострова. Изд-во: АН СССР. 1932.

10. Куплетский Б.М. Петрографический очерк Хибинских тундр // Минералы Хибинских и Ловозерских тундр. Изд-во: АН СССР. 1937. С. 13-48.

11. Сняткова О.Л., Михняк Н.К., Маркитахина Т.М., Принягин Н.И., Чапин В.А., Железова Н.Н., Дуракова А.Б., Евстафьев А.С., Подурушин В.Ф., Калинкин М.М. Отчет о результатах геологического доизучения и геохимических поисков на редкие металлы и апатит масштаба 1:50000, проведенных в пределах Хибинского массива и его обрамления за 1979-83 гг. Фонды Мурманкомприроды. 1983.

12. Ферсман А.Е. Геохимические дуги Хибинских тундр. ДАН СССР. Серия А. № 14. 1931. С. 367-376.

13. Ферсман А.Е. Полезные ископаемые Кольского полуострова. М.-Л. Изд-во: АН СССР. 1941. 345 с. 